\title{
Citra Destinasi sebagai Strategi Peningkatan Jumlah Wisatawan Danau Toba "Monaco of Asia" di Kabupaten Samosir
}

\section{Destination Image as a Strategy to Increase the Number of Tourists for Lake Toba "Monaco of Asia" in Samosir Regency}

\author{
Hengki Mangiring Parulian Simarmata* \& Roy Sahputra Saragih \\ Sekretari, Politeknik Bisnis Indonesia, Indonesia
}

Diterima:23 September 2020; Direview: 26 September 2020; Disetujui: 18 Oktober 2020

*Coresponding Email: hengkisimarmata.mm@gmail.com

\begin{abstract}
Abstrak
Danau Toba merupakan salah satu destinasi pariwisata prioritas yang memiliki kekayaan alam, budaya, dan sipritual. Dalam mewujudkan Danau Toba sebagai Monaco of Asia perlu memperhatikan berbagai aspek, salah satunya citra wisata Danau Toba di mata wisatawan. Peningkatan citra destinasi dipengaruhi oleh kepercayaan wisatawan terhadap objek wisata. Penelitian ini bertujuan untuk mengetahui bagaimana pengaruh citra destinasi terhadap keputusan kunjungan wisatawan di Kabupaten Samosir. Sampel yang digunakan dalam penelitian ini sebanyak 100 wisatawan yang sedang berkunjung di Kabupaten Samosir. Penelitian ini merupakan penelitian deskriptif dan kuantitatif. Teknik pengambilan data dengan menggunakan observasi dan pembagian kuesioner kepada wisatawan. Teknik pengambilan sampel dengan random sampling dengan analisis regresi linier sederhana. Hasil penelitian menunjukkan bahwa citra destinasi memiliki pengaruh positif signifikan terhadap kunjungan wisatawan. Dimana nilai koefisien determinasi $\left(\mathrm{R}^{2}\right)$ yaitu sebesar 0.258 yang artinya bahwa citra memiliki pengaruh sebesar 25.8\% terhadap keputusan kunjungan wisatawan ke Danau Toba Kabupaten Samosir sedangkan sisanya sebesar 74.2\% dipengaruhi oleh faktor lain yang tidak diteliti dalam penelitian ini seperti kondisi covid19, kualitas jasa, kinerja wisata dan lainnya.
\end{abstract}

Kata Kunci: Citra Destinasi, Pariwisata, Danau Toba.

\begin{abstract}
Lake Toba is one of the priority tourism destinations which has natural, cultural, and spiritual wealth. In realizing Lake Toba as the Monaco of Asia, it is necessary to pay attention to various aspects, one of which is the tourism image of Lake Toba in the eyes of tourists. The increase of destination image is influenced by the trust of tourists in tourist objects. This study aims to determine how the influence of destination image on tourist visit decisions in Samosir Regency. The sample used in this study were 100 tourists who were visiting in Samosir Regency. This research is descriptive and quantitative research. Data collection techniques using observation and distribution of questionnaires to tourists. The sampling technique was random sampling with a simple linear regression analysis. The results showed that destination image has a significant positive effect on tourist visits. Where the coefficient of determination (R2) is 0.258, which means that destination image has an influence of $25.8 \%$ on the decision to visit tourists to Lake Toba, Samosir Regency, while the remaining $74.2 \%$ is influenced by other factors not examined in this study such, covid-19 condition, service quality, tourism performance. and others.
\end{abstract}

Keywords: Destination Image, Tourism, Lake Toba

How to Cite: Simarmata, H.M.P \& Saragih, R.S., (2020). Citra Destinasi sebagai Strategi Peningkatan Jumlah Wisatawan Danau Toba "Monaco of Asia" di Kabupaten Samosir. Journal of Education, Humaniora and Social Sciences (JEHSS). 3 (2): 533-540. 


\section{PENDAHULUAN}

Pariwisata menjadi salah satu penyumbang terbesar devisa Indonesia. Pariwisata memiliki peran yang sangat besar dalam meningkatkan perekonomian dan pendapatan masyarakat. Pada kenyataannya potensi pariwisata yang ada di Indonesia belum dimaksimalkan dengan baik, hal ini disebabkan karena kurangnya perhatian pemerintah daerah dan pemerintah pusat dalam mengelola sumber daya alam dan sumber daya manusia yang ada.

Danau Toba merupakan salah satu objek wisata yang berada di Kabupaten Samosir Sumatera Utara. Danau Toba bukan sekedar dikenal dari keindahan alamnya tetapi juga budaya dan adat istiadat masyarakat sekitar. Wisatawan pada dasarnya berkunjung karena keindahan alam, iklim, sejarah, budaya, kuliner, dan keramah tamahannya (hospitality). Beberapa objek wisata unggulan yang terdapat di Kabupaten Samosir yang sering dikunjungi wisatawan ditunjukan pada tabel 1 .

\begin{tabular}{ll}
\multicolumn{2}{c}{ Tabel 1. Objek wisata Unggulan Kabupaten Samosir } \\
\hline No & Objek Wisata \\
\hline 1 & Makam Raja Sidabutar \\
2 & Kawasan Tuktuk Siadong \\
3 & Batu Kursi Parsidangan Siallagan \\
4 & Museum Hutabolon \\
5 & Pantai Pasir Putih Parbaba \\
6 & Aek Rangat Pangururan \\
7 & Dolok Holbung Sipege \\
8 & Aek Sipitu Dai \\
9 & Batu Sawan \\
10 & Air Terjun Effrata \\
11 & Air Terjun Naisogop \\
12 & Air Terjun Pangaribuan \\
\hline
\end{tabular}

Sumber : Dinas Pariwisata Kabupaten Samosir, 2019

Pada tahun 2020 kunjungan wisatawan mengalami kemerosotan yang sangat tajam hal ini disebabkan karena kondisi pandemik covid-19. Berdasarkan informasi dari Badan Pusat Statistika Kabupaten Samosir, kunjungan wisatawan mancanegara bulan juni 2020 sekitar 99 kunjungan atau mengalami penurunan sebanyak 99,53 persen dari 21.143 kunjungan pada bulan juni 2019. Pemerintah daerah dan pelaku Usaha Mikro, Kecil dan Menengah (UMKM) berusaha bertahan agar wisatawan dapat mengunjungi Danau Toba dengan menggunakan protokol kesehatan. Industri pariwisata diharapkan dapat bangkit salah satunya dengan meningkatkan citra destinasi wisata Danau Toba di mata masyarakat baik domestik maupun manca negara. Salah satu cara untuk meningkatkan kembali kunjungan wisatawan domestik dan mancanegara dengan meningkatkan citra destinasi Danau Toba. Citra destinasi dianggap sebagai salah satu faktor penting wisatawan dalam pemilihan destinasi wisata. Tujuan dari penelitian ini adalah untuk mengukur pengaruh citra (Image) terhadap keputusan kunjungan wisatawan di Kabupaten Samosir. Marpaung dalam Meidila (2014) menjelaskan bahwa pariwisata kegiatan rekreasi yang dilakukan diluar rumah dan dilakukan lebih dari 24 jam yang terdiri dari unsur manusia, ruang, dan waktu.

Peranan destinasi wisata bertujuan untuk meningkatkan kesejahteraan masyarakat. Menurut Hamzah, Hermawan dan Wigati (2018) dampak pariwisata terhadap ekonomi masyarakat adalah peningkatan pendapatan masyarakat, kesempatan kerja, meningkatnya distribusi manfaat dan keuntungan, kepemilikan dan kontrol ekonomi masyarakat, dampak pada pembangunan daerah. Dampak pembangunan pariwisata menurut Nasrullah et al, yaitu penyerapan tenaga kerja, menciptakan kesempatan usaha, mendorong pembangunan infrastruktur, peningkatan penerimaan pajak, peningkatan perekonomian masyarakat, peningkatan investasi di sektor pariwisata (Nasrullah et al, 2020).

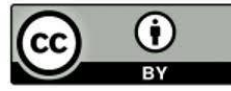


UU No.10 Tahun 2009 pasal 14 Tentang Kepariwisataan menjelaskan bahwa usaha pariwisata adalah daya tarik wisata, kawasan pariwisata, jasa transportasi, jasa perjalanan, jasa makanan dan minuman, penyedia akomodasi, penyelenggara kegiatan hiburan, penyelenggara kegiatan pertemuan, perjalanan insentif, konferensi dan pameran, jasa informasi, jasa konsultan pariwisata, jasa pramuwisata, wisata tirta dan spa (Jumadi, 2012; Meidila, 2014).

Citra destinasi Danau Toba sebagai danau terluas di Asia Tenggara merupakan point penting dalam keputusan wisatawan melakukan kunjungannya. Dengan citra destinasi yang baik dan dikenal maka memudahkan wisatawan untuk merencanakan liburannya. Citra diartikan sebagai ide, kesan, perasaan dan keyakinan terhadap sesuatu destinasi wisata (Kotler dan Keller, 2012). Citra destinasi adalah kesan tempat atau persepsi area (Handawan, 2015), sedangkan menurut Marsudi (2006) citra adalah sebuah nilai indikator potensi sebuah daerah.

Citra destinasi yang baik akan meningkatkan kunjungan wisata hal ini disebabkan karena citra mempengaruhi keputusan berkunjung dan minat untuk melakukan kunjungan ulang (Isnaini dan Abdillah, 2018). Faktor pembentuk citra dengan cara meningkatkan kualitas dan mutu, dapat dipercaya dan dihandalkan, kegunaan dan manfaat, pelayanan, risiko, dan harga (Mayasari, 2011; Simarmata, 2017, Lubis, 2020). Dimensi yang digunakan adalah untuk mengukur citra destinasi adalah perilaku ramah, posko keamanan, aktivitas wisata, informasi wisata, peta wisata, kebersihan, fasilitas wisata, restoran, penginapan, kegiatan seni, souvenir (Handawan, 2015; Suharyanto, 2019). Dimensi pengukuran citra adalah atribut, kepribadian, manfaat. Sedangkan dimensi yang digunakan untuk mengukur citra menurut Coker, Iyambo dan Otubanjo (2013) adalah simbol, logo, nama, warga dan slogan, sedangkan menurut Lin dan Lu mengukur citra dilihat dari popularitas, word of mouth yang baik dan komoditas yang ditawarkan. Citra destinasi dapat meningkatkan jumlah kunjungan wisatawan karena memudahkan wisatawan untuk melakukan pencarian informasi tempat yang akan dikunjungi (Kotler dan Keller, 2012).

Indikator pembentukan citra destinasi dibagi menjadi tiga yaitu secara kognitif (kepercayaan), afektif (perasaan) dan konatif. Citra secara kognitif mengacu pada kualitas, keramahan penduduk setempat, atraksi budaya, iklim dan cuaca serta harga layanan sedangkan citra secara afektif seperti imajinasi, harapan dan emosional seseorang mengenai tempat wisata Sedangkan konatif merupakan gabungan antara kognitif dan afektif dalam pengambilan keputusan (Rukmana dan Andjarwati, 2020). Hal yang sama juga dijelaskan oleh Utama (2016) bahwa citra dibentuk oleh komponen kognitif, afektif dan konatif.

Dalam penelitian ini indikator yang digunakan untuk mengukur citra adalah secara kognitif yaitu kepercayaan terhadap penyelenggara wisata, masyarakat di lokasi wisata, agen perjalanan, petugas wisata, produk dan jasa yang ditawarkan, sarana dan prasarana, informasi, iklan dan promosi destinasi wisata, citra danau toba, kredibilitas dinas pariwisata.

Keputusan konsumen melakukan pembelian dipengaruhi oleh faktor pengalaman (Putra, Chiwnita dan Sarina, 2019; Suharyanto, 2020). Keputusan dalam memilih tempat wisata dilakukan dengan tahapan pengenalan akan kebutuhan wisata, mencari informasi wisata, melakukan evaluasi dari berbagai alternatif tempat dan kemudian memutuskan tempat wisata yang akan dituju (Kotler dan Keller, 2012; Oktarina, 2012; Simarmata, Saragih dan Panjaitan, 2018). Dalam pengambilan keputusan wisatawan dihadapkan beberapa alternatif seperti produk atau jasa, yang akan dipilih, citra destinasi wisata yang akan dituju, kualitas layanan yang diharapkan, dan waktu melakukan kunjungan wisata (Hasibuan. dkk, 2019). Dalam proses pengambilan keputusan untuk melakukan kunjungan destinasi wisata, citra menjadi salah satu faktor penting dalam penga mbilan keputusan (Bawanti, 2016).

Dalam penelitian ini indikator yang digunakan untuk mengukur keputusan wisatawan melakukan kunjungan adalah pengenalan kebutuhan wisata, pencarian informasi tempat wisata, evaluasi berbagai alternatif destinasi dan keputusan kunjungan ke destinasi wisata.

Beberapa riset menunjukkan bahwa terhadap hubungan yang sangat erat antara citra destinasi dengan kunjungan wisata. Penelitian Bawanti (2016) menjelaskan bahwa keputusan dalam penentuan destinasi wisata ditentukan oleh pemahaman pribadi dan konseptual tentang apa yang diketahui dari destinasi wisata tersebut. Penelitian yang dilakukan di wisata Jayapura 
menunjukkan bahwa terdapat pengaruh positif dan signifikan citra terhadap pengembangan destinasi wisata. Hal yang sama juga dijelaskan oleh Wulandari (2013) bahwa citra Kabupaten purwakarta memiliki pengaruh yang positif dan signifikan terhadap keputusan kunjungan destinasi pariwisata dimana indikator yang digunakan untuk mengukur citra adalah kepribadian, reputasi destinasi wisata, nilai yang ditawarkan dan identitas dari destinasi wisata. Penelitian Isnaini dan Abdillah (2018) citra merek mempengaruhi keputusan wisatawan untuk melakukan kunjungan, meningkatkan kepuasan pengunjung dan minat kunjungan ulang. Dalam penelitian Isnaini dan Abdillah (2018) keputusan melakukan kunjungan dan kunjungan berulang dipengaruhi oleh unsur kognitif dan unsur afektif. Unsur kognitif yang mengacu pada kualitas layanan, keramahan penduduk setempat, atraksi pertunjukan, cuaca dan harga produk jasa yang ditawarkan dan unsur afektif mengacu pada perasaan yang dimiliki wisatawan terhadap objek wisata seperti harapan, imajinasi, dan pemikiran seseorang. Hasil penelitiannya menunjukkan bahwa citra merek memiliki pengaruh positif dan signifikan terhadap keputusan berkunjung dan minat melakukan kunjungan ulang (Isnaini dan Abdillah 2018).

Dalam penelitian Rukmana dan Andjarwati (2020), indikator yang digunakan untuk mengukur keputusan melakukan kunjungan dengan melakukan perencanaan, mencari informasi, dan memutuskan untuk melakukan kunjungan terhadap objek yang ditetapkan. Dari hasil penelitian dijelaskan bahwa terdapat pengaruh positif dan signifikan terhadap niat berkunjung wisatawan di Waduk Grobongan Kabupaten Bojonegoro.

\section{METODE PENELITIAN}

Metode penelitian dalam penelitian ini dengan menggunakan analisis deskriptif dan kuantitatif. Analisis deskriptif digunakan untuk menggambarkan sifat, keadaan, gejala atau kelompok (Sugiyono, 2012). Metode penelitian kuantitatif merupakan cara yang digunakan untuk menjawab masalah penelitian yang berkaitan dengan data berupa angka dan program statistik (Sugiyono, 2012).

Populasi penelitian adalah wisatawan yang berkunjung ke Kabupaten Samosir sebanyak 378.649 wisatawan berdasarkan data Badan Pusat Statistik Kabupaten Samosir tahun 2019. Dengan menggunakan rumus slovin maka sampel yang digunakan dalam penelitian ini berjumlah 100 orang (Sugiyono, 2012). Teknik pengambilan sampel dengan menggunakan non probability sampling.

Penelitian ini menggunakan sumber data primer dan sekunder. Data primer diperoleh dari penyebaran kuesioner kepada wisatawan, melakukan wawancara dan observasi ke Kabupaten Samosir. Sumber data sekunder diperoleh dari dokumen dinas pariwisata Kabupaten Samosir, data Badan Pusat Statistik Kabupaten Samosir, Buku dan Jurnal Manajemen Pariwisata.

Teknik analisis data dengan menggunakan analisis regresi linear sederhana dengan menggunakan bantuan SPSS 24. Uji validitas untuk mengukur valid tidaknya kuesioner. Hasil olahan penelitian didapat $r$ - hitung $>$ dari r-table 0.3 dengan taraf signifikan sebesar 0.000 lebih kecil dari 0.05 . Sehingga semua item dinyatakan valid mengukur citra destinasi dan keputusan kunjungan wisata. Berdasarkan hasil olahan data uji reliabilitas memiliki nilai cronbach alpha citra destinasi $0.852>0.6$ sedangkan nilai cronbach alpha untuk variabel keputusan kunjungan wisata $0.846>0.6$. Sehingga pertanyaan-pertanyaan dalam penelitian dianggap reliabel dan dapat digunakan sebagai alat ukur citra destinasi terhadap kunjungan wisata (Ghozali, 2016).

\section{HASIL DAN PEMBAHASAN}

Karakteristik responden dalam penelitian ini dimana berdasarkan jenis kelamin responden berjenis kelamin pria sebanyak 60 orang (60\%) dan wanita sebanyak 40 orang (40\%). Karakteristik responden berdasarkan usia dimana responden yang berusia diantara 17-25 tahun sebanyak $30(30 \%)$, usia diantara 26-34 tahun sebanyak 20 (20\%), usia diantara 35-44 tahun sebanyak 27 (27\%) dan usia diatas 45 tahun sebayak 23 (23\%). Karakteristik responden berdasarkan penghasilan perbulan dimana responden yang berpenghasilan 0-1 juta sebanyak $31 \%$, responden yang berpenghasilan 2-3 juta sebanyak 34\%, responden yang berpenghasilan 34 juta sebanyak 23\%, dan responden yang berpenghasilan diatas 5 juta sebanyak $12 \%$. 
Berdasarkan analisis deskriptif hasil olahan kuesioner dimana kepercayaan (kognitif) wisatawan terhadap citra destinasi Danau Toba dapat dijelaskan pada tabel 2 berikut ini.

Table 2. Tanggapan responden mengenai kepercayaan terhadap citra destinasi

\begin{tabular}{|c|c|c|c|c|}
\hline No & Citra Destinasi & $\begin{array}{l}\text { Persentase } \\
\text { Score }\end{array}$ & $\begin{array}{l}\text { Rentang } \\
\text { Score }\end{array}$ & Keterangan \\
\hline 1 & Kepercayaan responden terhadap penyelenggara wisata & $74.0 \%$ & 3.7 & Baik \\
\hline 2 & Kepercayaan responden terhadap masyarakat sekitar & $62.4 \%$ & 3.12 & Cukup \\
\hline 3 & $\begin{array}{l}\text { Kepercayaan responden terhadap agen perjalanan yang } \\
\text { memberikan jasa }\end{array}$ & $86.0 \%$ & 4.3 & Sangat Baik \\
\hline 4 & $\begin{array}{l}\text { Kepercayaan responden terhadap petugas wisata yang sedia } \\
\text { membantu wisatawan }\end{array}$ & $50.8 \%$ & 2.54 & $\begin{array}{l}\text { Kurang } \\
\text { Baik }\end{array}$ \\
\hline 5 & $\begin{array}{l}\text { Kepercayaan responden terhadap produk dan jasa yang } \\
\text { ditawarkan sesuai dengan harapan wisatawan }\end{array}$ & $52.6 \%$ & 2.63 & $\begin{array}{l}\text { Kurang } \\
\text { Baik }\end{array}$ \\
\hline 6 & Kepercayaan responden terhadap saranan dan prasarana & $86.4 \%$ & 4.32 & Sangat Baik \\
\hline 7 & $\begin{array}{l}\text { Kepercayaan responden terhadap informasi, iklan, brosur } \\
\text { yang diberitakan }\end{array}$ & $76.6 \%$ & 3.83 & Baik \\
\hline 8 & $\begin{array}{l}\text { Kepercayaan responden tentang citra Danau Toba sebagai } \\
\text { Monaco of Asia }\end{array}$ & $75.0 \%$ & 3.75 & Baik \\
\hline 9 & $\begin{array}{l}\text { Kepercayaan responden terhadap kredibilitas dinas } \\
\text { pariwisata dalam mengembangkan pariwisata Danau Toba }\end{array}$ & $73.2 \%$ & 3.66 & Baik \\
\hline & Total & $78.90 \%$ & 3.95 & Baik \\
\hline
\end{tabular}

Sumber: Hasil olahan data primer

Dari tabel 2 dapat dijelaskan bahwa kepercayaan wisatawan terhadap penyelenggara wisata Danau Toba dianggap sudah baik dengan nilai 74\% dengan rentang nilai 3.7 hal ini disebabkan karena banyaknya kegiatan-kegiatan wisata yang dilakukan baik dari pemerintah Kabupaten Samosir maupun pihak swasta beberapa kegiatan tahunan yang yang terdapat pada kalender kegiatan seperti festival gondang naposo, samosir band festival, sigalegale karnaval, samosir harverst, horja bius, samosir music international, samosir ultra marathon, festival ulos, festival solu bolon, christmast season dan festival sipinggan. Kepercayaan responden terhadap masyarakat sekitar dianggap cukup dengan persentase 62,4\% dengan nilai rentang 3.12. Hal ini dikarenakan wisatawan masing menganggap masyarakat masih ada yang tidak jujur dalam hal pemberian harga produk dan jasa yang ditawarkan. Contoh lain ketidak jujuran masyarakat adalah ketika membeli buah mangga di objek wisata dimana timbangan tidak sesuai, kualitas buah yang kurang baik. Hal lain yang membuat penilaian wisatawan cukup disebabkan kurangnya keramahan penduduk terhadap wisatawan. Dalam melakukan kunjungan wisata, wisatawan berpendapat bahwa mereka merasa nyaman dan tidak mengalami gangguan dari masyarakat sekitar. Kepercayaan responden terhadap agen perjalanan yang menawarkan jasa dianggap sangat baik dengan persentase $86,0 \%$ dengan rentang nilai 4.3. Hal ini dikarenakan agen perjalanan menawarkan layanan yang baik dan informasi yang cukup kepada wisatawan mulai dari akomodasi, restoran dan alat transportasi yang digunakan selama melakukan kunjungan wisata. Tanggapan responden terhadap kepercayaan petugas wisata yang siap membantu wisatawan dianggap kurang dengan persentase 50.8\% dengan rentang nilai 2.54 . Hal ini dikarenakan wisatawan merasa sulit untuk mencari petugas wisata ketika membutuhkan informasi tentang objek wisata atau keperluan selama melakukan kunjungan ke Danau Toba. Kepercayaan responden terhadap produk dan jasa yang ditawarkan dianggap kurang dengan persentase $52,6 \%$ dengan rentang nilai 2.63. Hal ini disebabkan karena kualitas produk dan layanan yang diberikan dianggap tidak sesuai atau terlalu mahal terutama untuk makanan dan minuman yang ditawarkan. Kepercayaan responden terhadap sarana dan prasarana dianggap sangat baik dengan persentase 86.4\% dengan rentang nilai 4.32 hal ini disebabkan Pemerintah Pusat dan Pemerintah Daerah sedang gencar melakukan perbaikan dan pembangunan sarana dan prasarana seperti pengadaan 
bus pariwisata samosir yang bisa diakses gratis yang di fasilitasi oleh dinas pariwisata Kabupaten Samosir dan dinas perhubungan Kabupaten Samosir, adanya kapal wisata berbentuk rumah adat batak dan patung sigale-gale, pembagunan dermaga jetty, perbaikan dermaga ambarita, dermaga simanindo, pelebaran jalan lingkar samosir dan pembangunan jembatan tano ponggol yang menghubungkan Pulau Samosir dengan Pulau Sumatera di Kecamatan Pangururan. Kepercayaan wisatawan terhadap iklan, brosur yang diberitakan dianggap baik dengan persentase $76.6 \%$ dengan rentang nilai 3.83, dimana wisatawan merasa mendapatkan informasi dari https: samosirkab.go.id yang berisi informasi kegiatan-kegiatan tahunan yang akan dilakukan dan brosur yang diperoleh dari hotel. Kepercayaan wisatawan terhadap citra Danau Toba sebagai Monaco of Asia dianggap baik dengan persentase 75\% dengan rentang nilai 3.75. Danau Toba dianggap sebagai danau terbesar di Asia Tenggara dan memiliki potensi wisata yang luar biasa baik dari alam, budaya dan kuliner. Kepercayaan responden terhadap kredibilitas dinas pariwisata dalam mengembangkan pariwisata dianggap baik dengan persentase $73.2 \%$ dengan rentang nilai 3.66 hal ini dinilai dari pembangunan pariwisata yang sedang berlangsung di Kabupaten Samosir.

Berdasarkan analisis kuantitatif dari hasil pengolahan data kuesioner dengan bantuan SPSS maka dapat dilihat pada tabel 3 sebagai berikut :

\begin{tabular}{|c|c|c|c|c|c|c|}
\hline & del & Sum of Squares & $\mathrm{df}$ & Mean Square & $\mathrm{F}$ & Sig. \\
\hline \multirow[t]{3}{*}{1} & Regression & 136.170 & 1 & 136.170 & 34.037 & $.000^{\mathrm{b}}$ \\
\hline & Residual & 392.070 & 98 & 4.001 & & \\
\hline & Total & 528.240 & 99 & & & \\
\hline
\end{tabular}

Sumber: Hasil olahan data primer, SPSS 2020

Bahwa nilai F hitung 34.037 lebih besar dari F tabel 1.658 dan nilai Sig hitung 0.000 lebih kecil dari Sig table 0.05. Hal ini berarti bahwa terdapat pengaruh positif signifikan antara citra destinasi terhadap keputusan kunjungan wisatawan di Kabupaten Samosir. Artinya semakin tinggi citra destinasi maka akan semakin mempengaruhi keputusan wisatawan untuk melakukan kunjungan ke Danau Toba Kabupaten Samosir. Penelitian ini juga didukung oleh beberapa penelitian sebelumnya yaitu penelitian Rukmana dan Andjarwati (2020), bahwa citra destinasi berpengaruh positif terhadap niat berkunjung wisatawan di Waduk Grobogan Kabupaten Bojongnegoro, penelitian Setiawan (2019) menjelaskan bahwa citra destinasi memiliki pengaruh positif dan signifikan terhadap niat berkunjung kembali di Kota Palembang Sumatera Selatan dan penelitian Wulandari (2013) menjelaskan bahwa citra Kabupaten Purwakarta memiliki pengaruh yang positif dan signifikan terhadap keputusan kunjungan destinasi pariwisata.

Untuk meningkatkan kepercayaan wisatawan terhadap destinasi wisata sebagai faktor penting dalam penentuan keputusan berkunjung ke Danau Toba maka perlunya melakukan peningkatan pelayanan terhadap penyelenggara wisata, petugas wisata, agen perjalanan, dan pegawai dinas pariwisata. Kegiatan untuk meningkatkan pelayanan dapat dilakukan dengan mengadakan seminar dan pelatihan sumber daya manusia. Masyarakat diharapkan lebih ramah lagi terhadap wisatawan dan dilibatkan dalam pengembangan pariwisata Danau Toba. Pembangunan sarana dan prasarana di kawasan Danau Toba perlu di awasi dan dijaga agar tetap memberikan manfaat bagi masyarakat dan tetap menjaga kelestarian lingkungan. Pengelolaan informasi yang baik di website, media sosial dan iklan diharapkan mampu meningkatkan citra Danau Toba sebagai Danau terbesar di kawasan Asia Tenggara menjadi Monaco of Asia.

\section{Koefisien Determinasi}

Untuk mengetahui besarnya pengaruh variabel citra destinasi (independen) terhadap variabel keputusan wisatawan untuk melakukan kunjungan (dependen). Nilai koefisien determinasi mempunyai interval nol sampai satu $\left(0 \leq R^{2} \leq 1\right)$. Jika $R^{2}=1$, berarti besarnya 
persentase sumbangan X terhadap Y maka diperoleh hasil pengolahan data SPSS sebagai berikut dijelaskan pada tabel 4 :

Table 4. Koefisien Determinasi

\begin{tabular}{lllll}
\hline \multicolumn{4}{l}{ Model Summary } \\
\hline Model & $\mathrm{R}$ & $\mathrm{R}$ Square & Adjusted R Square & Std. Error of the Estimate \\
\hline 1 & $.508^{\mathrm{a}}$ & .258 & .250 & 2.000 \\
\hline \multicolumn{5}{r}{ a. Predictors: (Constant), VARX } \\
Sumber: Hasil olahan data primer, SPSS 2020
\end{tabular}

Hasil koefisien determinan pada tabel 4 menunjukkan bahwa besarnya R Square adalah 0.258 yang artinya besarnya pengaruh citra destinasi terhadap keputusan wisatawan untuk melakukan kunjungan ke Danau Toba Kabupaten Samosir sebesar 25,8 \% dan sisanya 74,2\% dipengaruhi oleh faktor lain yang tidak diteliti dalam penelitian ini.

\section{SIMPULAN}

Berdasarkan hasil pembahasan dan analisis dapat dapat diambil kesimpulan bahwa citra destinasi berpengaruh positif dan signifikan terhadap keputusan kunjungan wisatawan di Danau Toba Kabupaten Samosir. Artinya semakin tinggi dan baik citra destinasi Danau Toba sebagai objek wisata maka semakin meningkatkan keputusan kunjungan wisatawan. Besarnya pengaruh variabel citra destinasi sebesar $25.8 \%$ dan sisanya $74.2 \%$ dipengaruhi oleh variabel lain yang tidak diteliti dalam penelitian ini seperti kondisi covid-19, kualitas jasa, kinerja wisata, dan lainnya. Oleh karena itu diharapkan pemerintah Kabupaten Samosir perlu meningkatkan citra destinasi agar wisatawan domestik maupun mancanegara memutuskan memilih liburan ke Danau Toba Kabupaten Samosir. Hal yang perlu diperhatikan seperti peningkatan kualitas sumber daya manusia dengan melakukan pelatihan dan seminar baik kepada masyarakat maupun petugas wisata. Disamping itu adanya penetapan standar harga dan kualitas terhadap produk dan jasa yang ditawarkan di kawasan objek wisata Danau Toba.

\section{UCAPAN TERIMAKASIH}

Terimakasih kepada Kementerian Riset dan Teknologi/Badan Riset dan Inovasi Nasional yang telah memberikan kepercayaan kepada peneliti untuk melakukan penelitian ini. Penelitian ini dibiayai oleh Direktorat Riset dan Pengabdian Masyarakat Direktorat Jenderal Penguatan Riset dan Pengembangan Kementerian Riset, Teknologi dan Pendidikan Tinggi tahun 2020. Terimakasih kepada Pimpinan Politeknik Bisnis Indonesia yang telah mendukung dan memfasilitasi dalam melakukan penelitian ini.

\section{DAFTAR PUSTAKA}

Bawanti, A. (2016). Analisis City Branding Dalam Pengembangan Destinasi Pariwisata Kabupaten Jayapura. Jurnal Media Wisata, 14(1): 365-381.

Coker, A. Iyamabo, J. \& Otubanjo. O. (2013). Investigating Service Responsiveness in Customer Perception of the Corporate Logo. International Journal of Business and Management, 8 (11): 38-50.

Ghozali, I. (2016). Aplikasi Analisis Multivariat dengan Program IBM SPSS23 (Edisi8). Semarang : Badan Penerbit Universitas Diponegoro.

Hamzah, F. Hermawan, H. \& Wigati. (2018). Evaluasi Dampak Pariwisata Terhadap Sosial Ekonomi Masyarakat Lokal. Jurnal Pariwisata, 5 (3): 195-202.

Handawan, Y.G. (2015). Pengaruh Citra Destinasi Pariwisata Waduk Sermo Terhadap Minat Wisatawan Berkunjung Ulang, Skripsi. Fakultas Ekonomi Universitas Sanata Dharma.

Hasibuan, J.S. Sitorus, A.K. Sirait, J.T. Tarigan, V.S.H. \& Marpaung, W. (2019). Keputusan Membeli Smartphone Ditinjau Dari Harga Diri Mahasiswa Fakultas Hukum Univesitas Medan Area. Journal of Education, Humaniora, and Social Sciences (JEHSS), 2 (1): 134-142. 
Hengki Mangiring Parulian Simarmata \& Roy Sahputra Saragih, Brand image sebagai Strategi Peningkatan Jumlah Wisatawan Danau Toba "Monaco of Asia" di Kabupaten Samosir

Hidayat, R.P., Ritonga, S. \& Suharyanto, A. (2020). Strategi Pemasaran Brothers Café dalam Membangun Brand image bagi Pengunjung di Kota Medan. Jurnal Ilmu Pemerintahan, Administrasi Publik dan Ilmu Komunikasi (JIPIKOM), 1(1) 2020: 33-37

Isnaini, P. R. \& Abdillah, Y. (2018). Pengaruh Citra Merek Destinasi Terhadap Keputusan Berkunjung dan Kepuasan Serta Dampaknya Pada Minat Kunjungan (Survei pada Pengunjung Taman Rekreasi Selecta Kota Batu yang termasuk dalam Kategori Generasi Millennial). Jurnal Administrasi Bisnis (JAB), 5(2): 122-129.

Jumadi. (2012). Integrasi Pemasaran Pariwisata Dalam Mewujudkan Kunjungan Kembali Wisatawan Ke Daerah Istimewa Yograkarta. Prosiding Seminar Nasional \& Call For Paper Forum Manajemen Indonesia (FMI) Ke-4 Indonesia Damily Business Sustainability: UII Yogyakarta 12-14 Novemver 2012.

Kotler, P. \& Keller, K. (2012). Marketing Management. Fourth Edition. England : Printice Hall.

Lubis, F. R. A., Suharyanto, A., Effendy, R., Meidasari, V. E., \& Shahnaz, L. (2020). Role of Facebook Advertising in Promoting Tourism in Asia. International Journal of Psychosocial Rehabilitation, 24(1).

Marsudi, A. (2006). Identifikasi Citra Pariwisata Kabupaten Kebumen. Skripsi. Fakultas Teknik Universitas Diponegoro.

Maulana, A. (2016). Pengaruh Kunjungan Wisatawan Mancanegara dan Perjalanan Wisata Nusantara Terhadap Penyerapan Tenaga Kerja Sektor Pariwisata Di Indonesia. Jurnal Kepariwisataan Indonesia. 11 (1) : 119-143.

Mayasari, L.I. (2011). Analisis Pengaruh Citra Merek, Persepsi Terhadap Kualitas, Nama Merek, Dan Brand Awareness Terhadap Keputusan Pembelian Sabun Pencuci Pakaian Bubuk Attack. Skripsi. Fakultas Ekonomi Universitas Diponegoro.

Meidila, M.M. (2014). Aktivitas Promosi Dinas Pariwisata dan Kebudayaan Kabupaten Wakatobi Dalam Meningkatkan Kunjungan Wisata Wakatobi Sulawesi Tenggara. Skripsi. Fakultas Ilmu Sosial dan Ilmu Politik Universitas Hasanuddin.

Nasrullah, et al. (2020). Pemasaran Pariwisata: Konsep, Perencanaan \& Implementasi. Medan : Yayasan Kita Menulis.

Oktarina, U. (2011). Persepsi Nasabah Tentang Sistem Penyampaian Jasa, Citra Merek dan Nilai Jasa Dalam Keputusan Penggunaan Jasa Bank Mandiri. Tesis. Magister Manajemen Unpad Bandung.

Putra, A.I.D. Chiwnita, O. \& Sarinah. (2019). Keputusan Pembelian ditinjau dari Persepsi Konsumen pada Mahasiswi Fakultas Ekonomi Universitas Pelita Harapan Medan. Journal of Education, Humaniora and SocialSciences (JEHSS). 2 (1): 55 - 63.

Rukmana, T.N. and Andjarwati, A.L. (2020). Motivasi Perjalanan, Citra Destinasi, dan E-WOM serta Pengaruh terhadap Niat Berkunjung (Studi pada Pengunjung Wisata Waduk Grobokan Kabupaten Bojonegoro). Jurnal Ilmu Manajemen, 8(2): 634-647.

Sandang, Y. \& Sanjaya, R.B. (2015). Pariwisata Indonesia Dalam Citra MOOI INDIE: Dahulu dan Sekarang. Jurnal Kritis. 24 (2) : 129-139.

Simarmata, H.M.P. (2017). Pengaruh Kualitas Jasa, Citra Perusahaan, dan Tingkat Suku Bunga Kredit Terhadap Keputusan Pengambilan Produk Kredit Mikro. Jurnal Murni Sadar. 7 (1) :16-31.

Simarmata, H.M.P. Saragih, D.Y. \& Panjaitan, N.J. (2018). Peningkatan Kualitas Layanan Untuk Kepuasan Pelanggan Hotel. Jurnal EK \& BI, 1 (1) : 43-51.

Sugiyono. (2012). Statistika untuk Penelitian. Bandung: Alfabeta.

Suharyanto, A., Barus, R. K. I., \& Batubara, B. M. (2020). Photography and Tourism Potential of Denai Kuala Village. Britain International of Humanities and Social Sciences (BIoHS) Journal, 2(1), 100-108. https://doi.org/10.33258/biohs.v2i1.153.

Suharyanto, A., Febryani, A., Wiflihani, Batubara. B.M., (2019). Village Government Policy on Tourism Management in Situngkir Village. Proceedings of the 2nd International Conference on Social Sciences and Interdisciplinary Studies (formerly ICCSSIS), ICCSIS 2019, 24-25 October 2019, Medan, North Sumatera, Indonesia.

Utama, I.G.B.R. (2016). Pemasaran Pariwisata. Bali: Universitas Dhayana Pura

Wulandari, T. (2013). Analisis Place Branding untuk Meningkatkan Citra Kabupaten Purwakarta serta Implikasinya terhadap Keputusan Mengunjungi Destinasi Pariwisata; (Survei terhadap Wisatawan Nusantara yang Berkunjung ke Kabupaten Purwakarta). Jurnal Ilmu Manajemen Dan Bisnis, 4(2): 1-12. 